\title{
Value of cerebrospinal fluid $\alpha$-synuclein species as biomarker in Parkinson's diagnosis and prognosis
}

\begin{abstract}
Since diagnosis of Parkinson's disease (PD) is mostly based on clinical criteria, it is almost impossible to formulate an early diagnosis, as well as a timely differential diagnosis versus other parkinsonisms. A great effort in searching reliable biomarkers both for early diagnosis and prognosis in PD is currently ongoing. Cerebrospinal fluid has been widely investigated as potential source for such biomarkers, with particular emphasis on $\alpha$-synuclein ( $\alpha$-syn) species. We reviewed all the clinical studies carried out so far on cerebrospinal fluid quantification of $\alpha$-syn species in PD. Current evidence supports the value of total and oligomeric $\alpha$-syn in PD diagnosis and in the differential diagnosis of PD and other parkinsonisms. Conversely, the role of $\alpha$-syn species in PD prognosis remains unsatisfactory.
\end{abstract}

Keywords: $\alpha$-synuclein $\bullet$ cerebrospinal fluid biomarkers $\bullet$ cognitive impairment $\bullet$ disease progression $\bullet$ early diagnosis $\bullet$ motor symptoms $\bullet$ parkinsonisms $\bullet$ Parkinson's disease - prognosis

At present, the clinical diagnosis of Parkinson's disease (PD) is unsatisfactory. It largely relies on clinical criteria, which makes it almost impossible to formulate an early diagnosis, as well as an accurate and timely differential diagnosis between PD and other parkinsonisms. Moreover, when considering the heterogeneity of PD subtypes, with their different clinical and prognostic features, we definitely have to admit that for this disease, similarly to other neurodegenerative diseases, we need reliable biomarkers both for early diagnosis and for prognosis prediction. The availability of these objective indicators would allow us to appropriately and promptly use forthcoming neuroprotective drugs.

In $\mathrm{PD}$ patients, we observe a progressive decline in both motor and nonmotor functions.

When speaking about biomarkers in neurodegenerative diseases, cerebrospinal fluid (CSF) represents a sort of 'gold standard' as source of information on the biochemical changes taking place in the brain and reflected in the periphery. It gives the unique opportunity to catch, at the same time, multiple indicators of the different pathophysiological cascades underlying the disease mechanisms [1]. $\alpha$-synuclein $(\alpha-$-syn) is the main actor in the pathogenesis of synucleinopathies, being the major component of the Lewy bodies. Mutations of the $\alpha$-syn gene are related with early-onset monogenic familial PD and are associated with increased risk for sporadic PD [2].

During the last 10 years, several studies have been carried out to measure CSF total $\alpha$-syn levels in PD and other parkinsonisms, with the primary aim to confirm its diagnostic value as biomarker of synucleinopathy. The great majority of these studies have shown a trend toward a decrease of CSF $\alpha$-syn levels in PD patients, although a large overlap between PD, other neurological diseases and controls is observed. Therefore, more recently, other $\alpha$-syn species (i.e., oligomeric $\alpha$-syn, phosphorylated $\alpha$-syn) have been considered to improve PD diagnostic accuracy. A few studies have also addressed the issue of the possible role of $\alpha$-syn as prognostic factor for motor and nonmotor symptoms [3,4].
Lucilla Parnetti*,1,₹, Claudia Cicognola ${ }^{2,4}$, Paolo Eusebi ${ }^{1,3}$ \& Davide Chiasserini ${ }^{1}$

'Section of Neurology, Department of Medicine, Center for Memory Disturbances, University of Perugia, Sant Andrea delle Fratte, 06132 Perugia, Italy ${ }^{2}$ Clinical Neurochemistry Laboratory, Department of Psychiatry \& Neurochemistry, Institute of Neuroscience \& Physiology, The Sahlgrenska Academy, University of Gothenburg, Mölndal, Sweden ${ }^{3}$ Health Planning Service, Regional Health Authority of Umbria, Department of Epidemiology, Perugia, Italy *Author for correspondence: lucilla.parnetti@unipg.it

†These authors contributed equally. 
Cognitive impairment represents one of the most common and devastating nonmotor symptoms of this disease. The risk of cognitive impairment increases with PD duration. Results from longitudinal studies have shown that mild cognitive deficits may be documented in approximately $25 \%$ of newly diagnosed patients, and dementia occurs in up to $80 \%$ of patients over the course of the disease $[5,6]$.

Therefore, the identification of biomarkers for $\operatorname{cog}$ nitive decline in PD is important in order to delay or prevent dementia.

In this systematic review, all the studies carried out so far on CSF measurement of $\alpha$-syn species in PD both as diagnostic and prognostic factor have been considered and reported. Issues about methodology of the CSF measurements have been also addressed.

\section{Search strategy}

References were identified by searching in PubMed databases from inception until 30 April 2015. We used the intersection of the following terms: 'cerebrospinal fluid', 'alpha-synuclein' and 'Parkinson's disease'. Search was not restricted to publications in English language. We obtained 161 records. Two reviewers have independently screened titles, abstracts and fulltexts. 32 publications were considered relevant and listed in our review. In case of disagreement on the relevance of individual papers, consensus was reached after discussion. References of selected articles were also checked to detect missing pieces of literature. We selected studies without any restrictions on settings and design excluding preclinical studies, conference proceedings, reviews and research investigating postmortem CSF. Studies were included if they assessed the role of $\alpha$-syn for differentiation between PD patients from healthy subjects or patients suffering from any other neurodegenerative diseases. Studies were eligible if at least one group of PD patients was included and total and/or oligomeric and/or phosphorylated $\alpha$-syn were quantified in CSF.

We have included also the results of Parkinson Progression Marker Initiative (PPMI [7]) study. The PPMI study is designed to establish a comprehensive set of clinical, imaging and biosample data that will be used to define biomarkers of PD progression. The full baseline characterization of the PPMI cohort has not yet been published; however, the paper of Kang 2013 analyzes a subset of these patients, while preliminary data on the full cohort are available in the website [8].

\section{Quantification of $\alpha$-synuclein species in cerebrospinal fluid}

$\alpha$ - synuclein is a small $(\sim 15 \mathrm{kDa})$ protein mostly localized at the presynaptic neuronal terminals. The spe- cific function of $\alpha$-syn is still a matter of debate; however, a plethora of different roles have been suggested, including synaptic plasticity, brain lipid metabolism and regulation of vesicle dynamics and trafficking [9]. Since the discovery of $\alpha$-syn mutations causative of PD [10] and the evidence that $\alpha$-syn is the main component of Lewy bodies [11], intense investigation aimed at understanding the role of this protein in PD etiopathogenesis.

On the other hand, the possibility to use $\alpha$-syn as a biomarker is relatively recent and derives from the discovery of its presence in biological fluids, including blood and CSF [12,13]. Given the observations on $\alpha$-syn metabolism in physiological and pathological conditions, total $\alpha$-syn is expected to be decreased in CSF of PD patients, possibly due to its accumulation as Lewy bodies in the brain tissue. The opposite (i.e., increase in CSF) should happen for $\alpha$-syn oligomers, as they are credited with being the soluble $\alpha$-syn species responsible for neurotoxicity. In recent years, most of the efforts have been focused on the measurement of $\alpha$-syn species in CSF of PD patients, to understand if this protein can be used as PD biomarker, in analogy to amyloid peptides assessment in Alzheimer's disease (AD) [14].

The most common methods to measure $\alpha$-syn species in biological fluids are immunochemical. The majority of the studies analyzed in this review used either in-house developed or commercially available ELISA assays to quantify the total content of $\alpha$-syn (Table 1). Other $\alpha$-syn species, such as oligomeric and phosphorylated $\alpha$-syn, have also been measured mostly using in-house ELISA assays. ELISA setups for total $\alpha$-syn are quite similar among the studies, using a monoclonal antibody for capture while a polyclonal antibody is used for detection of the analyte [15]. However, the antibodies used for capture and detection are often different. These differences caused a high variability among the published studies (Figure 1). Different groups have reported quite dissimilar ranges of total $\alpha$-syn in biological fluids and especially in CSF $[16,17]$. With the improvement of the current assays, the majority of the recent studies have reported the total $\alpha$-syn CSF levels in the low $(0.5-20) \mathrm{ng} / \mathrm{ml}$ range [18-20].

ELISA assays for total $\alpha$-syn are also commercially available from several manufacturers. Recently, the first interlaboratory study to establish the variability of an ELISA assay for total $\alpha$-syn has been performed. The study included a round robin evaluation of a research use only (RUO) $\alpha$-syn assay among 18 European laboratories experienced in CSF analysis. Several performance parameters were determined, including intra- and inter-assay variability, precision and dilution linearity. The laboratories analyzed CSF samples cen- 


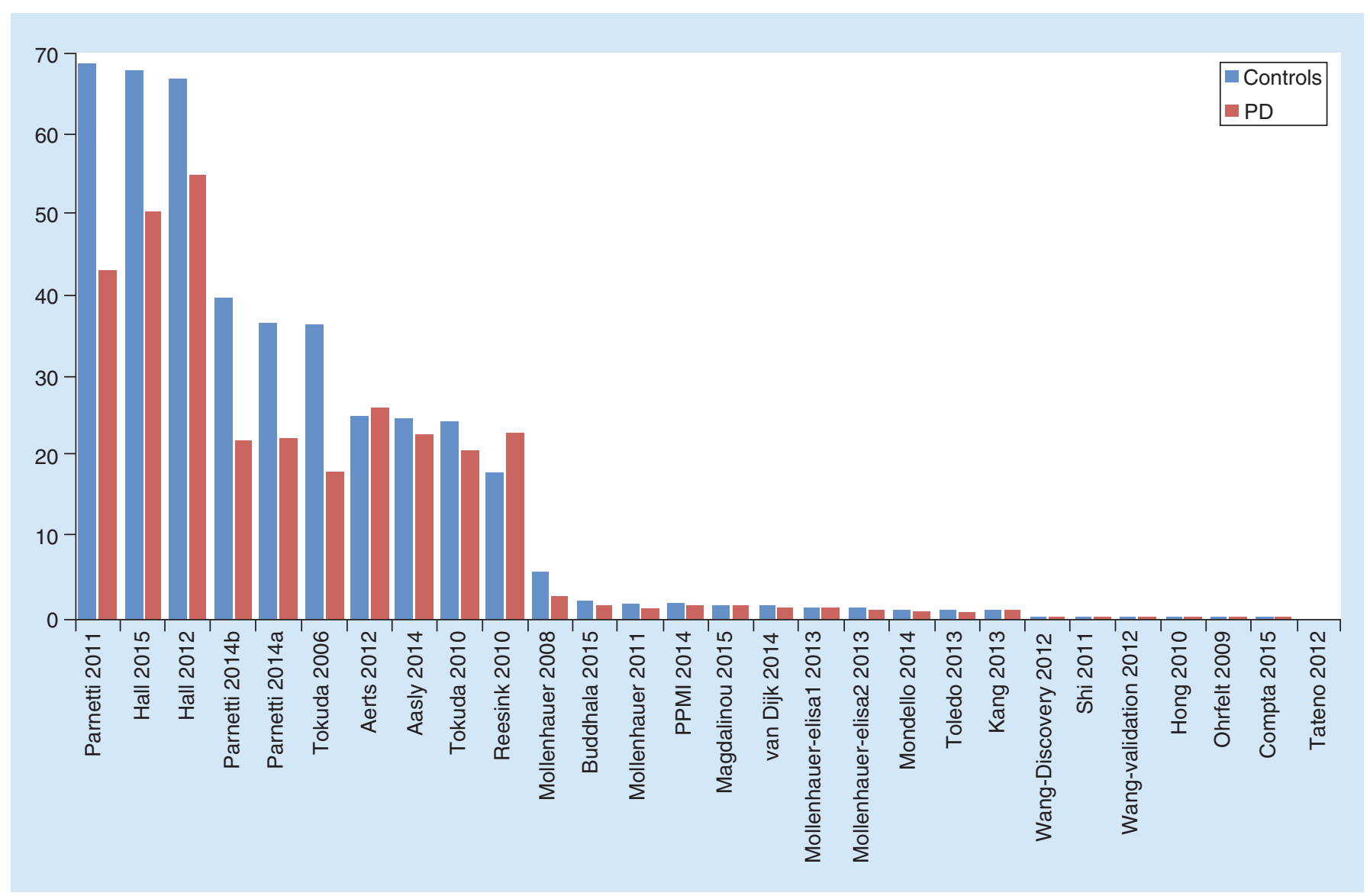

Figure 1. Mean values of total $\alpha$-synuclein level in controls and Parkinson's disease, across the studies reviewed.

trally provided with ELISA kits from the same batch, to reduce the variability linked to the kits. Raw luminescence data were also centrally analyzed using the same procedure to extract quantification data. The results highlighted a high variability of the total $\alpha$-syn absolute values among the laboratories involved, possibly due to the analytical procedures, namely interoperator variability and analytical instrumentation, calling for further optimization of the assay [21].

Oligomeric $\alpha$-syn has been mostly measured with solid-phase ELISAs [22,23]. The first studies used the same monoclonal antibody for capture and detection, postulating that only oligomeric synuclein would be responsible for the signal, due to the availability of free epitopes in some of the monomers composing the aggregates [22]. A major issue with the development of an assay for oligomeric $\alpha$-syn species resides in the availability of specific antibodies able to recognize only the aggregated forms and not the monomeric $\alpha$-syn. Recently, several groups started to produce antibodies specific for aggregated forms, such as oligomeric or fibrillar $\alpha$-syn, in order to increase the specificity of the assay, further clarifying which species are actually measured $[24,25]$. A recent paper described several con- formation-specific antibodies for oligomeric and fibrillar $\alpha$-syn [24]. These antibodies have a higher affinity for aggregated species and no reactivity or lower toward monomeric $\alpha$-syn, thus allowing an accurate detection of the aggregated species.

The second most frequently used technique to measure $\alpha$-syn is xMAPTM, also called Luminex [26]. This method is based on in-suspension immunodetection and quantification of the specific analyte. In solidphase ELISAs, the capture antibody is adsorbed on a microwell plate, which works as a solid support for the assay. Luminex assays use polystyrene beads coated with the capture antibody, which reacts with the analyte of interest. Detection uses a secondary antibody coupled to fluorescent tags. Due to the in-suspension format, the xMAP technique is theoretically capable to boost the maximum sensitivity of a solid-phase ELISA, increasing the possibility of interaction between the analyte and the coated beads suspended in the buffer. Furthermore, the technique is amenable to multiplexing, as differently color-coded beads can be coated with different capture antibodies, thus recognizing multiple targets. Hong and colleagues [26] performed the most comprehensive study using this method, 
finding lower CSF levels of total $\alpha$-syn in PD patients for $\alpha$-syn down to $0.009 \mathrm{ng} / \mathrm{mL}$. The xMAP method and ultimately being able to reach an assay sensitivity has also been used to quantify CSF Ser129-phosphor-

\begin{tabular}{|c|c|c|c|c|}
\hline Study (year) & Total $\alpha$-synuclein & $\begin{array}{l}\text { Oligomeric } \\
\alpha \text {-synuclein }\end{array}$ & $\begin{array}{l}\text { Phosphorylated } \\
\alpha \text {-synuclein }\end{array}$ & Ref. \\
\hline Aasly et al. (2014) & ELISA in-house & & & [30] \\
\hline Aerts et al. (2012) & ELISA in-house & & & [17] \\
\hline Borghi et al. (2000) & Western blot & & & [13] \\
\hline Buddhala et al. (2015) & $\begin{array}{l}\text { ELISA commercial (Covance/ } \\
\text { BioLegend) }\end{array}$ & & & [31] \\
\hline Compta et al. (2015) & $\begin{array}{l}\text { ELISA commercial (Invitrogen/ } \\
\text { Life Technologies) }\end{array}$ & ELISA in-house & & [18] \\
\hline Hall et al. (2012) & ELISA in-house & & & [32] \\
\hline Hong et al. (2010) & Luminex in-house & & & [26] \\
\hline Hu et al. (2015) & & $\begin{array}{l}\text { ELISA commercial } \\
\text { (CUSABIO) }\end{array}$ & & [33] \\
\hline Kang et al. (2013) & $\begin{array}{l}\text { ELISA commercial (Covance/ } \\
\text { BioLegend) }\end{array}$ & & & [34] \\
\hline Magdalinou et al. (2015) & NA & & & [19] \\
\hline Mollenhauer et al. (2008) & ELISA in-house & & & [35] \\
\hline Mollenhauer et al. (2011) & ELISA in-house & & & [36] \\
\hline Mollenhauer et al. (2013) & ELISA in-house & & & [37] \\
\hline Mondello et al. (2014) & $\begin{array}{l}\text { ELISA commercial (Covance/ } \\
\text { BioLegend) }\end{array}$ & & & [38] \\
\hline Ohrfelt et al. (2009) & ELISA in-house & & & [39] \\
\hline Park et al. (2011) & ELISA in-house & ELISA in-house & & [40] \\
\hline Parnetti et al. (2011) & ELISA in-house & & & [16] \\
\hline Parnetti et al. (2014a) & ELISA in-house & ELISA in-house & & [23] \\
\hline Parnetti et al. (2014b) & ELISA in-house & ELISA in-house & & [41] \\
\hline Reesink et al. (2010) & ELISA in-house & & & [42] \\
\hline $\begin{array}{l}\text { Parkinson Progression } \\
\text { Marker Initiative }\end{array}$ & $\begin{array}{l}\text { ELISA commercial (Covance/ } \\
\text { BioLegend) }\end{array}$ & & & \\
\hline Shi et al. (2011) & Luminex in house & & & [43] \\
\hline Stewart et al. (2014) & Luminex in-house & & & [44] \\
\hline Stewart et al. (2015) & Luminex in-house & & & [45] \\
\hline Tateno et al. (2012) & ELISA in-house & & & [46] \\
\hline Tokuda et al. (2006) & ELISA in-house & & & [15] \\
\hline Tokuda et al. (2010) & ELISA in-house & ELISA in-house & & [22] \\
\hline Toledo et al. (2013) & Luminex in-house & & & [47] \\
\hline van Dijk et al. (2014) & TR-FRET in-house & & & [29] \\
\hline Wang Y et al. (2012) & Luminex in-house & & Luminex in-house & [27] \\
\hline Wang H et al. (2012) & $\begin{array}{l}\text { ELISA commercial (Invitrogen/ } \\
\text { Life Technologies) }\end{array}$ & & & [48] \\
\hline Wennström et al. (2013) & $\begin{array}{l}\text { ELISA commercial (Invitrogen/ } \\
\text { Life Technologies) }\end{array}$ & & & [48] \\
\hline
\end{tabular}


ylated $\alpha$-syn in $\mathrm{PD}$, which were found significantly increased [27].

The third immunoassay method, used to quantify $\alpha$-syn species, is based on time-resolved Förster's resonance energy transfer [28]. This technique has been used to measure total CSF $\alpha$-syn in a cohort of PD patients. Reduced levels in PD with respect to control subjects were found; the range of the analyte was between 0.5 and $3 \mathrm{ng} / \mathrm{ml}$ [29].

\section{Results}

\section{Diagnostic value}

In Table 2, the results of studies on CSF $\alpha$-syn performance for distinguishing PD from controls, other parkinsonisms and other neurodegenerative diseases are reported. In a consistent proportion of them, $A D$ biomarkers $\left(\mathrm{A} \beta_{1-42}, \mathrm{t}\right.$-tau, $\mathrm{p}$-tau) were also investigated. All the studies report univariate test statistics for group comparisons. In 10 out of 28 , diagnostic accuracy measures, such as sensitivity and specificity, were also reported.

\section{Parkinson's disease versus controls}

The majority of the studies report lower CSF levels of total $\alpha$-syn in PD subjects as compared with controls [15-16,22-23,26-27,29,31-32,34-38,41,43,46-47,49]. By contrast, several studies reported comparable levels of CSF total $\alpha$-syn in PD patients and controls [13,17$18,27,30,39-40]$. When oligomeric $\alpha$-syn was quantified, in some studies, it was found to be higher in PD than controls [22,40-41], while in other reports, it did not significantly differ between groups $[18,23]$. The only study including phosphorylated $\alpha$-syn showed higher levels in PD versus controls [27]. No significant differences were found in total $\alpha$-syn levels between sporadic PD patients and LRRK2 mutation carriers [30].

\section{Parkinson's disease versus parkinsonisms}

Several studies analyzed the role of $\alpha$-syn in the differential diagnosis between PD and other parkinsonisms (Table 2). PD and multiple system atrophy (MSA) patients showed similar CSF total $\alpha$-syn levels in several studies $[17,32,36,43]$, while in two reports, MSA subjects showed lower levels [27,38]. Progressive supranuclear palsy (PSP) subjects showed either similar $[17,27]$ or higher $[32,38]$ levels of CSF total $\alpha$-syn when compared with PD. Phosphorylated $\alpha$-syn was found to be higher in PD than MSA and PSP patients [27]. Corticobasal degeneration cases had similar [32] or higher [38] CSF total $\alpha$-syn levels as compared with PD. No significant differences in CSF total $\alpha$-syn levels were found in vascular parkinsonism versus PD [17].

\section{Parkinson's disease versus dementias}

When compared with PD, Parkinson's disease with dementia (PDD) patients showed similar levels of CSF total $\alpha$-syn $[18,32,49]$, and higher CSF levels of oligomeric $\alpha$-syn [18]. Most of the studies report similarly reduced levels of CSF total $\alpha$-syn in PD and dementia with Lewy bodies (DLB) cohorts $[17,32,35,39,46]$. In one investigation [16], lower levels of total $\alpha$-syn were found in DLB and frontotemporal dementia patients, whereas Wennström et al. [49] found higher levels of total $\alpha$-syn in DLB subjects. Remarkably, AD patients have consistently shown higher CSF levels of total $\alpha$-syn as compared with PD $[26,32,35-36,43]$. Only in a study, no significant differences were found between $A D$ and PD [39]. In a study, higher levels of phosphorylated $\alpha$-syn were found in PD versus AD [49].

In half of the studies, at least one $\mathrm{AD}$ biomarker was investigated. In ten studies, $A \beta_{1-42}$, tau and $p$-tau where analyzed. In PD patients, $\alpha$-syn levels have been found to be positively correlated with total tau levels [18-19,31,34,41], p-tau [19,34] and $A \beta_{1-42}[18-19,31]$. Total tau/ $\alpha$-syn ratio could better differentiate between PD and other neurodegenerative dementias in a study [16]. Recently, oligomeric $\alpha$-syn has been shown to be positively correlated with tau [18].

\section{Prognostic value}

\section{Correlation with clinical parameters}

The results of studies on the correlation of total and oligomeric $\alpha$-syn with clinical parameters are reported in Table 3. No correlation between either total or oligomeric $\alpha$-syn in CSF and disease duration has been documented [16,18,23,26,30-32,34,36,38,40-42]. Only Magdalinou et al. [19] found a positive correlation between total $\alpha$-syn and disease duration, whereas oligomeric $\alpha$-syn showed opposite behavior in two studies (negative association in Aasly et al. [30], positive association in $\mathrm{Hu}$ et al. [33]). When analyzing the relationship between $\alpha$-syn concentrations at baseline and clinical rating scales, no significant correlations were found. No correlation between $\alpha$-syn and Hoehn and Yahr (H\&Y) stage has been found [18-19,23,26,30-31,38,4143,49], with the exception of three studies where lower CSF levels of total $\alpha$-syn $[15,34]$ and higher oligomeric $\alpha$-syn [30] correlated with a higher H\&Y score. The Unified Parkinson's disease rating score (UPDRS) rates the patient's disability in both cognitive and motor domain. Most studies focus on the correlation with motor symptoms and generally no significant correlation with the levels of $\alpha$-syn was found [23,27,29,4445]. Kang et al. [34] found a correlation between higher UPDRS score with higher levels of total $\alpha$-syn at baseline; by contrast, Stewart et al. [45] in one of the cohorts analyzed found a negative correlation of phosphory- 


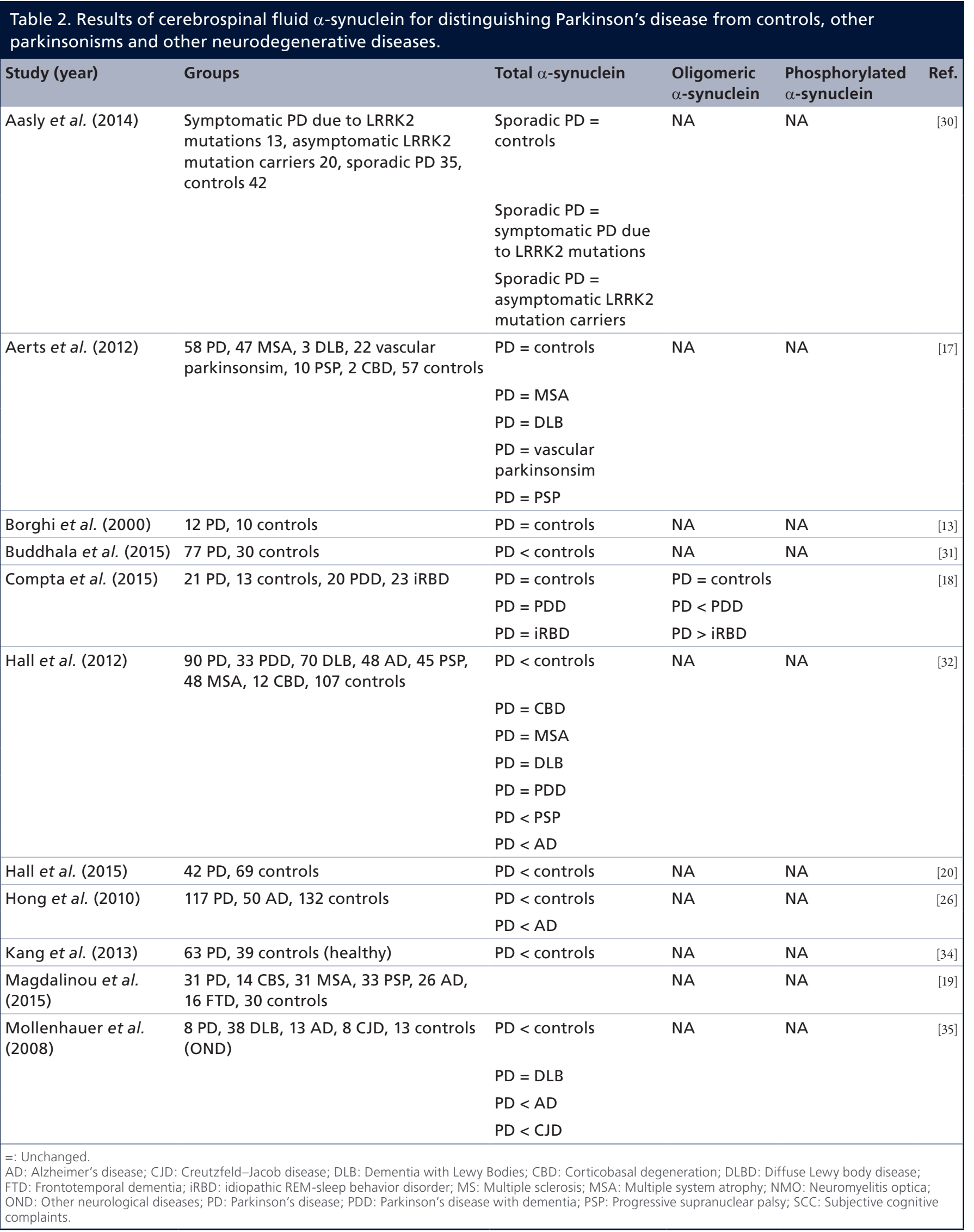


Table 2. Results of cerebrospinal fluid $\alpha$-synuclein for distinguishing Parkinson's disease from controls, other parkinsonisms and other neurodegenerative diseases (cont.).

\begin{tabular}{|c|c|c|c|c|c|}
\hline Study (year) & Groups & Total $\alpha$-synuclein & $\begin{array}{l}\text { Oligomeric } \\
\alpha \text {-synuclein }\end{array}$ & $\begin{array}{l}\text { Phosphorylated } \\
\alpha \text {-synuclein }\end{array}$ & Ref. \\
\hline \multirow[t]{3}{*}{$\begin{array}{l}\text { Mollenhauer et al. } \\
\text { (2011) }\end{array}$} & $\begin{array}{l}\text { Training set: } 51 \text { PD, } 29 \text { MSA, } 55 \text { DLB, } 62 \\
\text { AD, } 76 \text { controls (OND) }\end{array}$ & PD $<$ controls & NA & NA & [36] \\
\hline & & $\mathrm{PD}<\mathrm{DLB}$ & & & \\
\hline & & $P D<A D$ & & & \\
\hline \multirow[t]{3}{*}{ Mondello et al. (2014) } & $\begin{array}{l}52 \text { PD, } 34 \text { MSA, } 32 \text { PSP, } 12 \text { CBD, } 22 \\
\text { controls }\end{array}$ & $\mathrm{PD}<$ controls & NA & NA & [38] \\
\hline & & $\mathrm{PD}<\mathrm{CBD}$ & & & \\
\hline & & $\mathrm{PD}<\mathrm{PSP}$ & & & \\
\hline \multirow{2}{*}{ Ohrfelt et al. (2009) } & & $P D=D L B$ & & & \\
\hline & & $P D=A D$ & & & \\
\hline \multirow[t]{2}{*}{ Park et al. (2011) } & $\begin{array}{l}23 \mathrm{PD}, 29 \text { controls ( } 11 \text { symptomatic, } 18 \\
\text { OND), } 15 \mathrm{MS}\end{array}$ & $\mathrm{PD}=$ controls & PD $>$ controls & & [40] \\
\hline & & $P D=M S$ & $\mathrm{PD}>\mathrm{MS}$ & & \\
\hline $\begin{array}{l}\text { Parkinson Progression } \\
\text { Marker Initiative }\end{array}$ & 423 PD, 196 controls & PD $<$ controls & NA & NA & \\
\hline \multirow[t]{2}{*}{ Parnetti et al. (2011) } & $\begin{array}{l}38 \text { PD, } 32 \text { DLBD, } 48 \text { AD, } 31 \text { FTD, } 32 \\
\text { controls (OND). }\end{array}$ & $\mathrm{PD}<$ controls & NA & NA & [16] \\
\hline & & $P D>D L B$ & & & \\
\hline Reesink et al. (2010) & & $P D=D L B$ & & & \\
\hline \multirow[t]{3}{*}{ Shi et al. (2011) } & 126 PD, 32 MSA, 50 AD, 137 controls & PD $<$ controls & NA & NA & [43] \\
\hline & & $\mathrm{PD}=\mathrm{MSA}$ & & & \\
\hline & & $P D<A D$ & & & \\
\hline \multirow[t]{4}{*}{ Tateno et al. (2012) } & $\begin{array}{l}9 \text { AD, } 6 \text { DLBD, } 11 \text { PD, } 11 \text { MSA, } 11 \\
\text { controls (OND) }\end{array}$ & $\mathrm{PD}<$ controls & NA & NA & [46] \\
\hline & & $\mathrm{PD}=\mathrm{MSA}$ & & & \\
\hline & & $P D=D L B$ & & & \\
\hline & & $P D<A D$ & & & \\
\hline Tokuda et al. (2006) & $\begin{array}{l}33 \text { PD, } 38 \text { controls ( } 9 \text { healthy, } 29 \text { with } \\
\text { OND) }\end{array}$ & $\mathrm{PD}<$ controls & NA & NA & {$[15]$} \\
\hline $\begin{array}{l}\text { =: Unchanged. } \\
\text { AD: Alzheimer's disease; CJD: } \\
\text { FTD: Frontotemporal dementi } \\
\text { OND: Other neurological dise } \\
\text { complaints. }\end{array}$ & $\begin{array}{l}\text { Creutzfeld-Jacob disease; DLB: Dementia with Lewy } \\
\text { a; iRBD: idiopathic REM-sleep behavior disorder; MS: } \\
\text { ases; PD: Parkinson's disease; PDD: Parkinson's disease }\end{array}$ & $\begin{array}{l}\text { Bodies; CBD: Corticoba } \\
\text { Multiple sclerosis; MSA } \\
\text { e with dementia; PSP: P }\end{array}$ & $\begin{array}{l}\text { neration; DLBD: } \\
\text { system atrophy; } \\
\text { e supranuclear pa }\end{array}$ & $\begin{array}{l}\text { ffuse Lewy body disea } \\
\text { JMO: Neuromyelitis op } \\
\text { sy; SCC: Subjective cos }\end{array}$ & \\
\hline
\end{tabular}




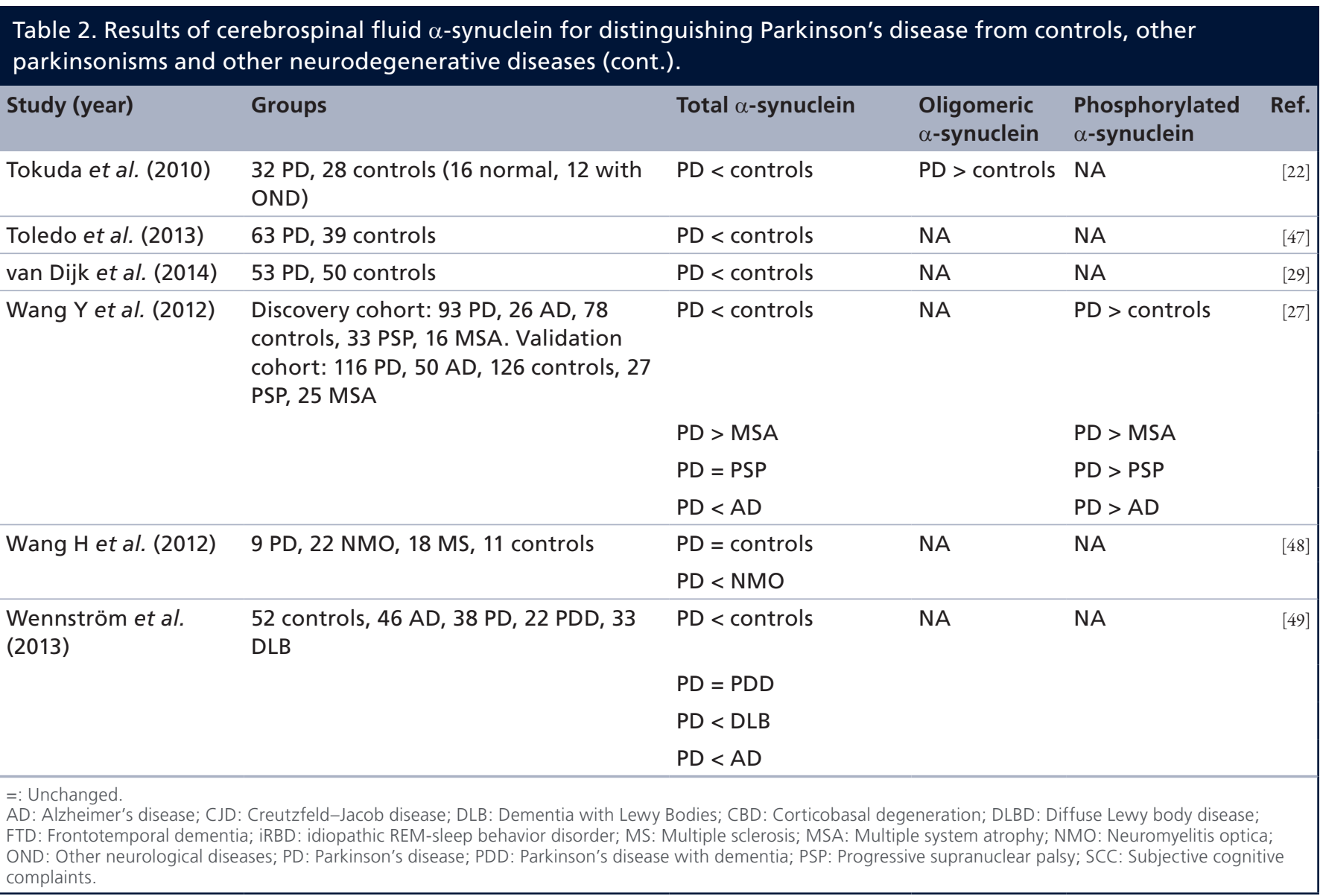

lated $\alpha$-syn with UPDRS score. When considering cognitive symptoms, no correlation was found between the levels of total or oligomeric $\alpha$-syn and neuropsychological assessment or Mini Mental State Examination scores $[16,18,23,26,31-32,34,40-41,49]$.

\section{Cognitive decline}

The issue of a possible prognostic value of $\alpha$-syn with respect to cognitive impairment in PD has been addressed in a few recent studies, giving inconsistent results (Table 4). When measured by cognitive speed testing, higher levels of total $\alpha$-syn have been found to be associated with cognitive decline in PD [20], suggesting that lower $\alpha$-syn can be predictive of a positive cognitive outcome [44]. In a cohort of PD patients followed-up for 4 years, no significant correlations of Montreal Cognitive Assessment and Mini Mental State Examination scores with CSF total and oligomeric $\alpha$-syn were found [41].

\section{Worsening of motor symptoms}

No significant correlations between total $\alpha$-syn concentrations and H\&Y and UPDRS scores have been observed in some studies [43,44], while in another inves- tigation [20], higher levels of CSF total $\alpha$-syn predicted worsening in motor symptoms (Table 4).

\section{Conclusion \& future perspective}

In the last years, an increasing number of studies measuring CSF $\alpha$-syn species in PD has been carried out, with the aim to further highlight their possible role as biomarkers. The great majority of studies have considered the measurement of total $\alpha$-syn; in a smaller proportion also oligomeric forms have been analyzed. Definitely insufficient are the data about other species (i.e., phosphorylated $\alpha$-syn).

We systematically assessed the available studies in order to evaluate if the value of CSF $\alpha$-syn species either as diagnostic or prognostic biomarkers in PD can be claimed.

The investigations are quite heterogeneous in terms of patients studied and methods followed for $\alpha$-syn determination. Some important issues emerged in terms of $\alpha$-syn determination and its utility in terms of prognostic and diagnostic marker for PD.

\section{Technical issues on $\alpha$-synuclein determination} The most common methods used for measuring CSF 
Table 3. Results of correlation analyses between cerebrospinal fluid $\alpha$-synuclein and clinical parameters in Parkinson's disease cohorts.

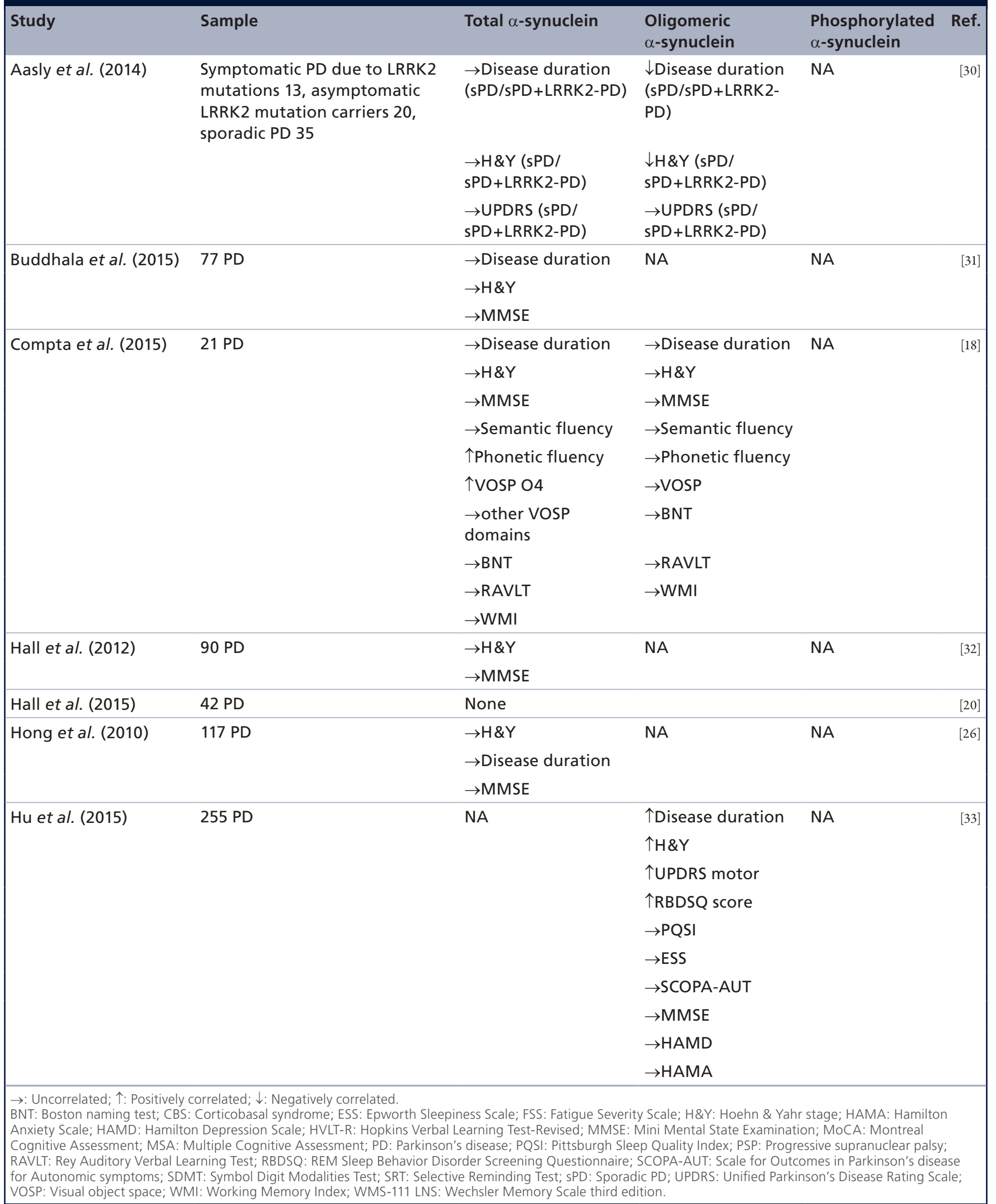


Table 3. Results of correlation analyses between cerebrospinal fluid $\alpha$-synuclein and clinical parameters in Parkinson's disease cohorts (cont.).

\begin{tabular}{|c|c|c|c|c|c|}
\hline Study & Sample & Total $\alpha$-synuclein & $\begin{array}{l}\text { Oligomeric } \\
\alpha \text {-synuclein }\end{array}$ & $\begin{array}{l}\text { Phosphorylated } \\
\alpha \text {-synuclein }\end{array}$ & Ref. \\
\hline \multicolumn{2}{|l|}{ Hu et al. (2015) (cont.) } & & \multicolumn{3}{|l|}{$\rightarrow \mathrm{FSS}$} \\
\hline Kang et al. (2013) & 63 PD & $\begin{array}{l}\rightarrow \text { Disease duration } \\
\downarrow \text { H\&Y } \\
\uparrow \text { UPDRS motor } \\
\rightarrow \text { MoCA } \\
\rightarrow \text { Semantic fluency } \\
\rightarrow \text { HVLT-R } \\
\rightarrow \text { SDMT } \\
\rightarrow \text { WMS-III LNS }\end{array}$ & NA & NA & [34] \\
\hline $\begin{array}{l}\text { Magdalinou et al. } \\
\text { (2015) }\end{array}$ & 31 PD, 14 CBS, 31 MSA, 33 PSP & $\begin{array}{l}\text { } \text { Disease duration } \\
\rightarrow \mathrm{H} \& \mathrm{Y}\end{array}$ & NA & NA & [19] \\
\hline $\begin{array}{l}\text { Mollenhauer et al. } \\
\text { (2011) }\end{array}$ & $51 \mathrm{PD}$ in the training set & $\rightarrow$ Disease duration & NA & NA & [36] \\
\hline Mondello et al. (2014) & $52 \mathrm{PD}$ & $\begin{array}{l}\rightarrow \text { Disease duration } \\
\rightarrow \mathrm{H} \& \mathrm{Y}\end{array}$ & NA & NA & [38] \\
\hline Park et al. (2011) & $23 \mathrm{PD}$ & $\begin{array}{l}\rightarrow \text { Disease duration } \\
\rightarrow \mathrm{H} \& \mathrm{Y} \\
\rightarrow \mathrm{MMSE}\end{array}$ & $\begin{array}{l}\rightarrow \text { Disease duration } \\
\rightarrow \mathrm{H} \& \mathrm{Y} \\
\rightarrow \mathrm{MMSE}\end{array}$ & NA & [40] \\
\hline Parnetti et al. (2011) & 38 PD & $\rightarrow$ Disease duration & NA & NA & [16] \\
\hline Parnetti et al. (2014a) & $\begin{array}{l}71 \text { PD ( } 8 \text { of } 44 \text { carriers of a GBA } \\
\text { mutation) }\end{array}$ & $\begin{array}{l}\rightarrow \text { Disease duration } \\
\rightarrow \text { H\&Y } \\
\rightarrow \text { UPDRS }\end{array}$ & $\begin{array}{l}\rightarrow \text { Disease duration } \\
\rightarrow \text { H\&Y } \\
\rightarrow \text { UPDRS }\end{array}$ & NA & [23] \\
\hline Parnetti et al. (2014b) & $44 \mathrm{PD}$ & $\begin{array}{l}\rightarrow \text { Disease duration } \\
\rightarrow \mathrm{H} \& \mathrm{Y}\end{array}$ & $\begin{array}{l}\rightarrow \mathrm{H} \& \mathrm{Y} \\
\rightarrow \text { Disease duration }\end{array}$ & NA & [41] \\
\hline Reesink et al. (2010) & $18 \mathrm{PD}$ & $\begin{array}{l}\rightarrow \text { Disease duration } \\
\rightarrow \mathrm{H} \& \mathrm{Y}\end{array}$ & NA & NA & [42] \\
\hline Shi et al. (2011) & 39 PD & $\begin{array}{l}\rightarrow \text { UPDRS } \\
\rightarrow \mathrm{H} \& \mathrm{Y}\end{array}$ & NA & NA & [43] \\
\hline Stewart et al. (2014) & 304 PD & $\begin{array}{l}\rightarrow \text { UPDRS total } \\
\rightarrow \text { UPDRS motor } \\
\rightarrow \text { SDMT } \\
\rightarrow \text { SRT } \\
\rightarrow \text { New Dot test }\end{array}$ & NA & NA & [44] \\
\hline $\begin{array}{l}\text { M: Uncorrelated; } \uparrow: \text { Positively } \\
\text { BNT: Boston naming test; CBS } \\
\text { Anxiety Scale; HAMD: Hamiltc } \\
\text { Cognitive Assessment; MSA: I } \\
\text { RAVLT: Rey Auditory Verbal Le } \\
\text { for Autonomic symptoms; SDI } \\
\text { VOSP: Visual object space; WI }\end{array}$ & $\begin{array}{l}\text { orrelated; } \downarrow \text { : Negatively correlated. } \\
\text { Corticobasal syndrome; ESS: Epworth Sleepi } \\
\text { n. Depression Scal;; HVLTTR: Hopkins Verbal L L } \\
\text { lultiple Cognitive Assessment; PD: Parkinson' }\end{array}$ & $\begin{array}{l}\text { ness Scale; FSS: Fatigue Sev } \\
\text { Learning Test-Revised; MMS } \\
\text { 's disease; PQSI: Pittsburgh } \\
\text { rder Screening Questionnai } \\
\text { ee Reminding Test; sPD: Spo } \\
\text { lechsler Memory Scale third }\end{array}$ & $\begin{array}{l}\text { y Scale; H\&Y: Hoehn \& Yaht } \\
\text { Mini Mental State Examinati } \\
\text { ep Quality Index; PSP: Progr } \\
\text { SCOPA-AUT: Scale for Outc } \\
\text { lic PD; UPDRS: Unified Parki } \\
\text { ition. }\end{array}$ & $\begin{array}{l}\text { stage; HAMA: Hamilton } \\
\text { on; MOCA: Montreal } \\
\text { :ssive supranuclear palsy; } \\
\text { Smes in Parkinson's disea } \\
\text { son's Disease Rating Scal }\end{array}$ & \\
\hline
\end{tabular}


Table 3. Results of correlation analyses between cerebrospinal fluid $\alpha$-synuclein and clinical parameters in Parkinson's disease cohorts (cont.).

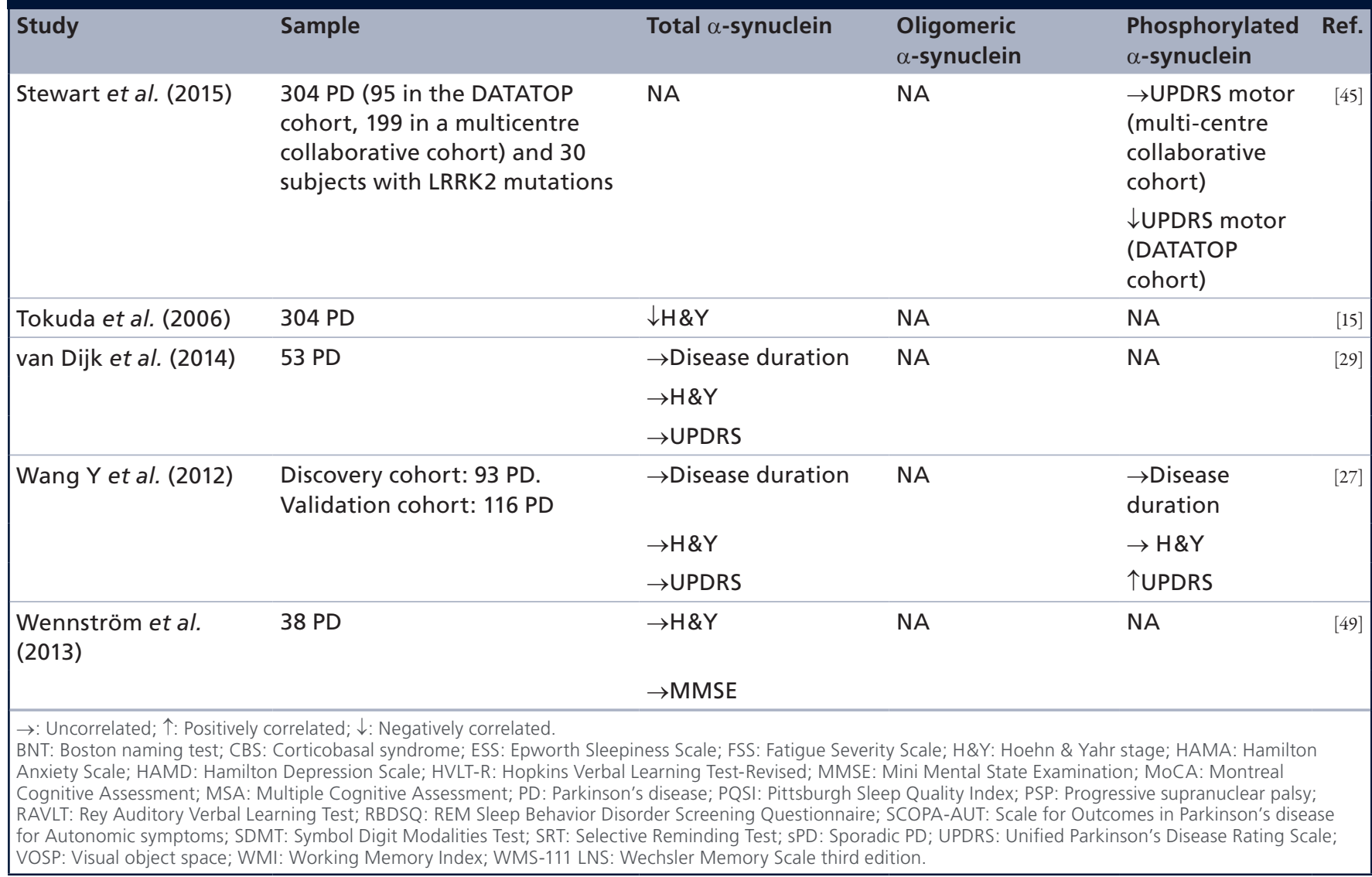

$\alpha$-syn species are immunoenzymatic, using a wide variety of assays, either in-house developed or commercially available. Based on the current evidence, it can be claimed that, in CSF of PD patients, levels of total $\alpha$-syn are lower than in control subjects. This result is consistently reported in the literature, including two recent meta-analyses [50,51]. In most of the studies assessing oligomeric $\alpha$-syn, this species has been found to be higher in CSF of PD patients than in controls. The only available study investigating phosphorylated $\alpha$-syn showed that also this species shows higher levels in $\mathrm{PD}$ as compared with controls.

However, several technical issues are to be solved before CSF $\alpha$-syn can be considered as a useful PD biomarker. Studies aimed at understanding the influence of preanalytical and analytical factors on $\alpha$-syn determination are warranted. In fact, it has been shown that variables such as type of tubes, storage temperature, centrifugation, time before storage, freeze/thaw cycles have a significant effect on the determination of AD biomarkers [52]. Systematic studies about the influence of preanalytical factors on $\alpha$-syn CSF levels are lacking; a recent work highlighted how the high interassay vari- ability of $\alpha$-syn levels may be related to batch-to-batch differences of the immunoassays used [21].

A fundamental preanalytical variable for the measurement of $\alpha$-syn in CSF is blood contamination, as $\alpha$-syn is particularly abundant in erythrocytes. Hemoglobin has been proposed as specific marker of blood contamination [26], but no specific cut-off value to be used as an exclusion/inclusion parameter has been univocally determined. Therefore, further studies are needed to clarify this issue, which may have decisive implications for quality control of the CSF samples.

In future, international efforts and a close collaboration between the researchers and immunoassay vendors will become essential, in order to qualify standard operating procedures for CSF collection and storage suitable for $\alpha$-syn, but also reference materials for quality control and kit manufacturing.

\section{Diagnostic \& prognostic performance}

With respect to PD clinical staging, the spectrum of patients varies across studies, ranging from preclinical stages to de novo PD cases or patients in advanced phases. Clinical symptoms of the disease have been assessed 
Table 4. Results of using cerebrospinal fluid $\alpha$-synuclein for tracking progression of clinical parameters in Parkinson's disease.

\begin{tabular}{|c|c|c|c|c|c|}
\hline Study (year) & Sample & Total $\alpha$-synuclein & $\begin{array}{l}\text { Oligomeric } \\
\alpha \text {-synuclein }\end{array}$ & $\begin{array}{l}\text { Phosphorylated } \\
\alpha \text {-synuclein }\end{array}$ & Ref. \\
\hline Hall et al. (2015) & $42 \mathrm{PD}$ & 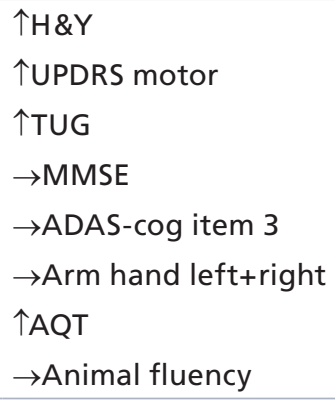 & NA & NA & [20] \\
\hline Parnetti et al. (2014b) & $44 \mathrm{PD}$ & $\begin{array}{l}\rightarrow \text { MMSE } \\
\rightarrow \text { MoCA }\end{array}$ & $\begin{array}{l}\rightarrow \text { MMSE } \\
\rightarrow \text { MoCA }\end{array}$ & NA & {$[41]$} \\
\hline Stewart et al. (2015) & $\begin{array}{l}304 \text { PD (95 in the DATATOP cohort, } \\
199 \text { in a multicenter collaborative } \\
\text { cohort) and } 30 \text { subjects with LRRK2 } \\
\text { mutations }\end{array}$ & NA & NA & $\rightarrow$ UPDRS motor & {$[45]$} \\
\hline
\end{tabular}

using different tools for measuring motor and cognitive domains. Several studies refer to small groups of patients.

Several studies analyzed the role of $\alpha$-syn species in the differential diagnosis between PD and other parkinsonisms (MSA [53], PSP, corticobasal degeneration, vascular parkinsonism) with inconsistent findings. When compared with PD, both PD with dementia and DLB patients did not significantly differ with respect to CSF levels of $\alpha$-syn species. It is of interest that AD patients show higher CSF total $\alpha$-syn levels when compared with PD cases, reflecting the different pathophysiological involvement of $\alpha$-syn in these diseases.

With respect to the role of CSF $\alpha$-syn species as prognostic biomarkers, the majority of the studies showed no correlation with disease duration, clinical rating scales and neuropsychological assessment. The few available longitudinal studies gave inconsistent findings both for motor and cognitive domains.

We can conclude that the combined CSF assessment of total and oligomeric $\alpha$-syn enables us to improve our diagnostic accuracy in distinguishing PD from other neurological diseases and controls, while their prognostic value is questionable.

\section{Future perspective}

In order to improve our knowledge in this field, thus getting closer to a clinical use of CSF biomarkers in PD diagnosis, we do need to improve the standardization of the available assays, thus reducing the large interlaboratory variability.

Also, international collaborative networks following homogeneous protocols for enrolling large clinically well-characterized PD cohorts are highly needed.

In the future, CSF biomarkers might also serve as theragnostic markers after disease-modifying treatments.

Although the use of CSF biomarkers in PD is limited by the lack of optimal candidates, some clinical trials have incorporated CSF analysis as a measure of efficacy or target engagement, or for exploratory analysis [54]. To this purpose, CSF $\alpha$-syn is now being explored as a surrogate marker of treatment efficacy and/or target engagement in patients with PD or other synucleino- 
pathies. Active immunization with $\alpha$-syn in patients with PD is also being investigated in Phase I trials [54].

Finally, the need to create a composite CSF biomarkers profile reflecting different neurodegenerative processes taking place in PD brain as dynamic phenomena along the course of the disease should be implemented. In order to be able to detect the disease in its premotor phase - as a conditio sine qua non for a rationale use of disease-modifying agents, the strategy represented by the combination of different markers is mandatory.

Financial \& competing interests disclosure

The authors have no relevant affiliations or financial in- volvement with any organization or entity with a financial interest in or financial conflict with the subject matter or materials discussed in the manuscript. This includes employment, consultancies, honoraria, stock ownership or options, expert testimony, grants or patents received or pending, or royalties.

No writing assistance was utilized in the production of this manuscript.

\section{Open access}

This work is licensed under the Creative Commons Attribution-NonCommercial 4.0 Unported License. To view a copy of this license, visit http://creativecommons.org/licenses/bync-nd/4.0/

\section{Executive summary}

Methodological issues about measurement of $\alpha$-synuclein species in cerebrospinal fluid

- ELISA is the prominent method of measurement.

- Measurements carried out since 2000 are highly heterogeneous.

- The results of a recent international validation study highlighted the high variability of the total $\alpha$-synuclein $(\alpha-s y n)$ absolute value among laboratories.

\section{Diagnostic value of cerebrospinal fluid $\alpha$-synuclein species}

- Total $\alpha$-syn levels are lower in Parkinson's disease (PD) compared with controls.

- Oligomeric $\alpha$-syn levels are higher in PD as compared with controls.

- Combination of total and oligomeric $\alpha$-syn helps in differential diagnosis between PD and other diseases.

- Few studies investigated the prognostic value of cerebrospinal fluid $\alpha$-syn species in PD, generating inconsistent data.

\section{Future perspective}

- Need for improvement of assay standardization.

- Research community should spend more effort in larger studies aiming at creating a composite cerebrospinal fluid profile including multiple neurodegeneration biomarkers.

\section{References}

1 Parnetti L, Castrioto A, Chiasserini D et al. Cerebrospinal fluid biomarkers in Parkinson disease. Nature Rev. Neurol, 9(3), 131-140 (2013).

2 Alonso-Navarro H, Jimenez-Jimenez FJ, Garcia-Martin E, Agundez JA. Genomic and pharmacogenomic biomarkers of Parkinson's disease. Curr. Dru Metabol. 15(2), 129-181 (2014).

3 Pfeiffer RF. Non-motor symptoms in Parkinson's disease. Parkinsonism Relat. Disord. doi:10.1016/j. parkreldis.2015.09.004 (2015) (Epub ahead pf print).

4 Schrag A, Sauerbier A, Chaudhuri KR. New clinical trials for nonmotor manifestations of Parkinson's disease. Mov. Disord. 30(11), 1490-1504 (2015).

5 Hely MA, Reid WG, Adena MA, Halliday GM, Morris JG. The Sydney multicenter study of Parkinson's disease: the inevitability of dementia at 20 years. Mov. Disord. 23(6), 837-844 (2008).

6 Aarsland D, Andersen K, Larsen JP, Lolk A, Kragh-Sorensen P. Prevalence and characteristics of dementia in Parkinson disease: an 8-year prospective study. Arch. Neurol. 60 (3), 387-392 (2003).

7 Parkinson's Progression Markers Initiative. http://www.ppmi-info.org
8 The Parkinson's Progression Marker Initiative (PPMI) assessment of clinical, imaging and CSF PD biomarkers. http://www.ppmi-info.org

9 Vekrellis K, Xilouri M, Emmanouilidou E, Rideout HJ, Stefanis L. Pathological roles of alpha-synuclein in neurological disorders. Lancet Neurol. 10(11), 1015-1025 (2011).

10 Polymeropoulos MH, Lavedan C, Leroy E et al. Mutation in the alpha-synuclein gene identified in families with Parkinson's disease. Science 276(5321), 2045-2047 (1997).

11 Spillantini MG, Schmidt ML, Lee VM, Trojanowski JQ, Jakes R, Goedert M. Alpha-synuclein in Lewy bodies. Nature 388(6645), 839-840 (1997).

12 El-Agnaf OM, Salem SA, Paleologou KE et al. Alphasynuclein implicated in Parkinson's disease is present in extracellular biological fluids, including human plasma. FASEB J. 17(13), 1945-1947 (2003).

13 Borghi R, Marchese R, Negro A et al. Full length $\alpha$-synuclein is present in cerebrospinal fluid from Parkinson's disease and normal subjects. Neurosci. Lett. 287(1), 65-67 (2000).

14 Mollenhauer B. Quantification of alpha-synuclein in cerebrospinal fluid: how ideal is this biomarker for 
Parkinson's disease? Parkinsonism Relat. Disord. 20(Suppl. 1), S76-S79 (2014).

15 Tokuda T, Salem SA, Allsop D et al. Decreased alphasynuclein in cerebrospinal fluid of aged individuals and subjects with Parkinson's disease. Biochem. Biophys. Res. Commun. 349(1), 162-166 (2006).

16 Parnetti L, Chiasserini D, Bellomo G et al. Cerebrospinal fluid Tau/alpha-synuclein ratio in Parkinson's disease and degenerative dementias. Mov. Disord. 26(8), 1428-1435 (2011).

17 Aerts MB, Esselink RA, Abdo WF, Bloem BR, Verbeek MM. CSF alpha-synuclein does not differentiate between parkinsonian disorders. Neurobiol. Aging 33(2), 430 e431-e433 (2012).

18 Compta Y, Valente T, Saura J et al. Correlates of cerebrospinal fluid levels of oligomeric- and total-alphasynuclein in premotor, motor and dementia stages of Parkinson's disease. J. Neurol. 262(2), 294-306 (2015).

19 Magdalinou NK, Paterson RW, Schott JM et al. A panel of nine cerebrospinal fluid biomarkers may identify patients with atypical parkinsonian syndromes. J. Neurol. Neurosurg. Psychiatr. doi:10.1136/jnnp-2014-309562 (2015) (Epub ahead of print).

20 Hall S, Surova Y, Ohrfelt A, Zetterberg H, Lindqvist D, Hansson O. CSF biomarkers and clinical progression of Parkinson disease. Neurology 84(1), 57-63 (2015).

21 Kruse N, Mollenhauer B. Validation of a commercially available enzyme-linked immunoabsorbent assay for the quantification of human alpha-synuclein in cerebrospinal fluid. J. Immunol. Method. doi:10.1016/j.jim.2015.08.003 (2015) (Epub ahead of print).

22 Tokuda T, Qureshi MM, Ardah MT et al. Detection of elevated levels of alpha-synuclein oligomers in CSF from patients with Parkinson disease. Neurology, 75(20), 1766-1772 (2010).

23 Parnetti L, Chiasserini D, Persichetti E et al. Cerebrospinal fluid lysosomal enzymes and alpha-synuclein in Parkinson's disease. Mov. Disord. 29(8), 1019-1027 (2014).

24 Vaikath NN, Majbour NK, Paleologou KE et al. Generation and characterization of novel conformation-specific monoclonal antibodies for alpha-synuclein pathology. Neurobiol. Dis. 79, 81-99 (2015).

25 Fagerqvist $\mathrm{T}$, Lindstrom V, Nordstrom E et al. Monoclonal antibodies selective for alpha-synuclein oligomers/protofibrils recognize brain pathology in Lewy body disorders and alpha-synuclein transgenic mice with the disease-causing A30P mutation. J. Neurochem. 126(1), 131-144 (2013).

26 Hong Z, Shi M, Chung KA et al. DJ-1 and alpha-synuclein in human cerebrospinal fluid as biomarkers of Parkinson's disease. Brain 133(Pt 3), 713-726 (2010).

27 Wang Y, Shi M, Chung KA et al. Phosphorylated alphasynuclein in Parkinson's disease. Sci. Transl. Med. 4(121), 121ra120 (2012).

28 Bidinosti M, Shimshek DR, Mollenhauer B et al. Novel onestep immunoassays to quantify alpha-synuclein: applications for biomarker development and high-throughput screening. J. Biol. Chem. 287(40), 33691-33705 (2012).
29 van Dijk KD, Bidinosti M, Weiss A, Raijmakers P, Berendse HW, van de Berg WD. Reduced alpha-synuclein levels in cerebrospinal fluid in Parkinson's disease are unrelated to clinical and imaging measures of disease severity. Eur. J. Neurol. 21(3), 388-394 (2014).

30 Aasly JO, Johansen KK, Bronstad G et al. Elevated levels of cerebrospinal fluid alpha-synuclein oligomers in healthy asymptomatic LRRK2 mutation carriers. Front. Aging Neurosci. 6, 248 (2014).

31 Buddhala C, Campbell MC, Perlmutter JS, Kotzbauer PT. Correlation between decreased CSF alpha-synuclein and Abeta(1)(-)(4)(2) in Parkinson disease. Neurobiol. Aging 36(1), 476-484 (2015).

32 Hall S, Ohrfelt A, Constantinescu R et al. Accuracy of a panel of 5 cerebrospinal fluid biomarkers in the differential diagnosis of patients with dementia and/or parkinsonian disorders. Arch. Neurol. 69(11), 1445-1452 (2012).

33 Hu Y, Yu SY, Zuo LJ et al. Parkinson disease with REM sleep behavior disorder: features, alpha-synuclein, and inflammation. Neurology 84(9), 888-894 (2015).

34 Kang JH, Irwin DJ, Chen-Plotkin AS et al. Association of cerebrospinal fluid beta-amyloid 1-42, T-tau, P-tau181, and alpha-synuclein levels with clinical features of drug-naive patients with early Parkinson disease. JAMA Neurol. 70 (10), 1277-1287 (2013).

35 Mollenhauer B, Cullen V, Kahn I et al. Direct quantification of CSF alpha-synuclein by ELISA and first cross-sectional study in patients with neurodegeneration. Exp. Neurol. 213(2), 315-325 (2008)

36 Mollenhauer B, Locascio JJ, Schulz-Schaeffer W, SixelDöring F, Trenkwalder C, Schlossmacher MG. $\alpha$-synuclein and tau concentrations in cerebrospinal fluid of patients presenting with parkinsonism: a cohort study. Lancet Neurol. 10(3), 230-240 (2011).

37 Mollenhauer B, Trautmann E, Taylor P et al. Total CSF alpha-synuclein is lower in de novo Parkinson patients than in healthy subjects. Neurosci. Lett. 532, 44-48 (2013).

38 Mondello S, Constantinescu R, Zetterberg H, Andreasson U, Holmberg B, Jeromin A. CSF alpha-synuclein and UCH-L1 levels in Parkinson's disease and atypical parkinsonian disorders. Parkinsonism Relat. Disord. 20(4), 382-387 (2014).

39 Ohrfelt A, Grognet P, Andreasen N et al. Cerebrospinal fluid alpha-synuclein in neurodegenerative disorders - a marker of synapse loss? Neurosci. Lett. 450(3), 332-335 (2009).

40 Park MJ, Cheon SM, Bae HR, Kim SH, Kim JW. Elevated levels of alpha-synuclein oligomer in the cerebrospinal fluid of drug-naive patients with Parkinson's disease. J. Clin. Neurol. 7(4), 215-222 (2011).

41 Parnetti L, Farotti L, Eusebi P et al. Differential role of CSF alpha-synuclein species, tau, and Abeta 42 in Parkinson's disease. Front. Aging Neurosci. 6, 53 (2014).

42 Reesink FE, Lemstra AW, van Dijk KD et al. CSF alphasynuclein does not discriminate dementia with Lewy bodies from Alzheimer's disease. J. Alzheimers Dis. 22(1), 87-95 (2010).

43 Shi M, Bradner J, Hancock AM et al. Cerebrospinal fluid biomarkers for Parkinson disease diagnosis and progression. Ann. Neurol. 69(3), 570-580 (2011). 
44 Stewart T, Liu C, Ginghina C et al. Cerebrospinal fluid alpha-synuclein predicts cognitive decline in Parkinson disease progression in the DATATOP cohort. Am. J. Pathol. 184(4), 966-975 (2014).

45 Stewart T, Sossi V, Aasly JO et al. Phosphorylated alphasynuclein in Parkinson's disease: correlation depends on disease severity. Acta Neuropathol. Commun. 3, 7 (2015). Tateno F, Sakakibara R, Kawai T, Kishi M, Murano T. Alpha-synuclein in the cerebrospinal fluid differentiates synucleinopathies (Parkinson disease, dementia with Lewy bodies, multiple system atrophy) from Alzheimer disease. Alzheimer Dis. Assoc. Disord. 26(3), 213-216 (2012).

47 Toledo JB, Korff A, Shaw LM, Trojanowski JQ, Zhang J. CSF alpha-synuclein improves diagnostic and prognostic performance of CSF tau and Abeta in Alzheimer's disease. Acta Neuropathol. 126(5), 683-697 (2013).

, Wang K, Xu W et al. Cerebrospinal fluid alphasynuclein levels are elevated in multiple sclerosis and neuromyelitis optica patients during replase. J. Neurochem. 122(1), 19-23 (2012).

49
Wennstrom M, Surova Y, Hall S et al. Low CSF levels of both alpha-synuclein and the alpha-synuclein cleaving enzyme neurosin in patients with synucleinopathy. PLoS ONE 8(1), e53250 (2013).

50 Gao L, Tang H, Nie Ket al. Cerebrospinal fluid alphasynuclein as a biomarker for Parkinson's disease diagnosis: a systematic review and meta-analysis. Int. J. Neurosci. 125(9), 645-654 (2015).

51 Sako W, Murakami N, Izumi Y, Kaji R. Reduced alphasynuclein in cerebrospinal fluid in synucleinopathies: evidence from a meta-analysis. Mov. Disord. 29(13), 1599-1605 (2014).

52 del Campo M, Mollenhauer B, Bertolotto A et al. Recommendations to standardize preanalytical confounding factors in Alzheimer's and Parkinson's disease cerebrospinal fluid biomarkers: an update. Biomarkers Med. 6(4), 419-430 (2012).

53 Laurens B, Constantinescu R, Freeman R et al. Fluid biomarkers in multiple system atrophy: a review of the MSA Biomarker Initiative. Neurobiol. Dis. 80, 29-41 (2015).

54 Lleo A, Cavedo E, Parnetti L et al. Cerebrospinal fluid biomarkers in trials for Alzheimer and Parkinson diseases. Nature Rev. Neurol. 11(1), 41-55 (2015). 